\title{
Flying a kite
}

DOI:

10.1080/03098265.2018.1463975

\section{Document Version}

Accepted author manuscript

Link to publication record in Manchester Research Explorer

\section{Citation for published version (APA):}

Pánek, J., Paszto, V., \& Perkins, C. (2018). Flying a kite: playful mapping in a multidisciplinary field-course. Journal of Geography in Higher Education, 42(3), 317-336. https://doi.org/10.1080/03098265.2018.1463975

\section{Published in:}

Journal of Geography in Higher Education

\section{Citing this paper}

Please note that where the full-text provided on Manchester Research Explorer is the Author Accepted Manuscript or Proof version this may differ from the final Published version. If citing, it is advised that you check and use the publisher's definitive version.

\section{General rights}

Copyright and moral rights for the publications made accessible in the Research Explorer are retained by the authors and/or other copyright owners and it is a condition of accessing publications that users recognise and abide by the legal requirements associated with these rights.

\section{Takedown policy}

If you believe that this document breaches copyright please refer to the University of Manchester's Takedown Procedures [http://man.ac.uk/04Y6Bo] or contact uml.scholarlycommunications@manchester.ac.uk providing relevant details, so we can investigate your claim.

\section{OPEN ACCESS}




\title{
Flying a kite: playful mapping in a multidisciplinary field-course
}

Running heads:

Journal of Geography in Higher Education

J. Pánek et al.

Pánek Jiří a, * AQ1

Pászto Vít b, c

Perkins Chris d

${ }^{a}$ Department of Development and Environmental Studies, Palacký University, Olomouc, Czech Republic $A Q 2$

${ }^{b}$ Department of Geoinformatics, Palacký University, Olomouc, Czech Republic

${ }^{c}$ Department of Computer Science and Applied Mathematics, Moravian University College, Olomouc, Czech Republic

${ }^{d}$ School of Environment, Education and Development, University of Manchester, Manchester, UK

Corresponding author. Email: JirkaPanek@gmail.com

Received 04 Dec 2017; Accepted 04 Apr 2018

(C) 2018 Informa UK Limited, trading as Taylor \& Francis Group

\begin{abstract}
This article reviews the potential of kite mapping as part of an interdisciplinary and multinational field course. It situates kite mapping as a low cost, high quality, participatory approach, in relation to field use of maps, arguing that research might usefully attend to more than simply the skills acquired during the field exercise and the technicalities of the innovation.

Evidenced from two day-long workshops on the Maltese island of Gozo we describe practical issues involved in making the mapping work. We draw on descriptions of field practice and deploy a multi-method evaluation of staff and student reactions and experiences to explore pedagogic aspects of kite mapping. We conclude that the practices of kite mapping significantly impact upon the value of the mapping technique, and highlight how creative and playful mapping processes implicit in the technique might usefully be deployed in other field contexts.
\end{abstract}

\section{Keywords}

Kite mapping 
playful geography

research-led teaching

DIY mapping

\section{Introduction}

Kite Aerial Photography (KAP) is a low-cost remote sensing method used for scientific surveys, meteorological observations and for military surveillance. Kites have been used for lifting photographic equipment for centuries (see de Beauffort \& Dusariez, 1995) and were very popular before being largely replaced by planes in the 1920s and 1930s (Aber \& Gałązka, 2000) and drones at the beginning of the twenty-first century. A renaissance of kite-mapping started in the 1980s and William Warner ( 1996 ) coined the term kiteography for the use of kite aerial photography in creating large-scale topographic maps based on photogrammetric principles. Since then, kites have been used in landscapes as diverse as high mountains in Norway (Wundram \& Löffler, 2008) and Indonesian islands (Currier, 2015 ). They have also been used across many different application areas, including periglacial geomorphological mapping (Boike \& Yoshikawa, 2003 ), observation of Antarctic penguins (Fraser, Carlson, Duley, Holm, \& Patterson, 1999), monitoring of seabirds (Delord et al., 2015), the mapping of intertidal landscapes (Bryson, Johnson-Roberson, Murphy, \& Bongiorno, 2013 ), wetland protection (Aber, Aber, Pavri, Volkova, \& Penner, 2006; Aber, Eberts, \& Aber, 2005 ), property survey (Aber \& Aber, 2003 ), and in field teaching (Sander, 2014). The technique offers a very affordable bottom-up and DIY (Do-It-Yourself) approach in which researchers themselves can potentially generate very high quality images and maps (Duffy \& Anderson, 2016). Instead of having to access expensive mapping data sets, with licence restrictions upon use (although some of them are becoming open - e.g.

Copernicus datasets), kite mapping serves up a shared and user-oriented approach targeted to specific needs, in which resolution, coverage and quality can be designed to fit different purposes - and in which the sharing of participant skills can lead to outcomes that are frequently more appropriate than those that might arise from using commercial products. Technological change has facilitated these developments, with cheap digital cameras delivering very high quality results, but kite-mapping also depends strongly upon the culture of open software development, for the processing of results. As such its increasing use is part of the trend towards citizen science and the participatory ethos embodied by the technique places it within the democratization of cartography (Rød, Ormeling, \& van Elzakker, 2001 )) and the crowdsourcing of mapping that has grown in pace in the new millennium (Sui, Elwood, \& Goodchild, 2013). Guidance for using the technique already exists - see for example Grassrootsmapping.org (2010).

In this paper we explore the possibilities of implementing kite-mapping during university field courses, building upon published work (Sander, 2014) about the potential of the technique. By way of contrast to Sander (2014), which is largely technical and emphasizes skill acquisition in image 
interpretation, we highlight its capacity to do much more than simply convey spatial perception and enhance interpretive skills relating to the landscape. As such, our focus is in part pedagogic and the main research question concerns the suitability of kite-mapping for geography field teaching and learning, as a student-led and group-based exploratory research activity. So this paper is a multifaceted exploration of how a data collection technique might operate during field practice, but it also concerns the impacts upon learning and the affects of kite mapping on student and staff experiences.

Our paper describes kite-mapping during two workshops as part of an interdisciplinary and multinational field-trip to the island of Gozo, Malta. In two years twenty-three students (12 in 2016 and 11 in 2017) from four European universities (Universities of Manchester and Warwick, UK; Palacký University Olomouc, Czech Republic, and Utrecht University, the Netherlands) took part in the kitemapping workshop as an elective during a sensory mapping day, in which groups were invited to compare smell, sound and vision, in terms of what these sensory modalities might contribute towards field-based exploratory and playful fieldwork. We situate this pedagogic innovation in the wider context of university field course development and the role that maps have played in the field experience. We then describe the detail of how we implemented kite-mapping, exploring low-cost technical tools and open-source software that were used to set up the mapping kit. We describe the practicalities of mapping the field site, and creating a seamless aerial image in GeoTIFF format, which was stitched into a final map product. However, the paper also evaluates the potential of the technique as part of a more creative and active participatory use of mapping in the field and as such moves beyond the technical and methodological to consider some of the practices through which such an innovation might be delivered.

\section{Field-based learning}

Field-based learning has a long history in the discipline of geography, with local inquiry in realworld contexts being carried out as part of the teaching of geography in schools and universities from the mid-nineteenth century onwards (Ploszajska, 1998). According to Kent, Gilbertson, and Hunt (1997, p. 313) "fieldwork is widely regarded as an essential part of undergraduate education in geography... and field experience is also seen as vital for the development of students as qualified practitioners in all aspects of geography". As an embedded and situated mode of inquiry, field-work has changed to reflect developing technology and pedagogic and disciplinary practice. In their definitive guide, Phillips and Johns (2012) chart the increasing popularity of residential and overseas field courses. Moreover, the mode of learning has shifted over this period, as student-led inquiry has frequently come to supplant teacher-led investigation (Higgitt, 1996).

Observation remains central to this process but is increasingly complemented by problem-solving and the practicing of research techniques. As such, the field experience delivers a great opportunity to develop students' skills, equipping them for dissertation research, and for the world of work. Learning 
becomes more closely related to research in this context, instead of being somehow separate (Healey, 2005 ). Problem-based and inquiry-based learning with the goal of deep learning has emerged as an important part of this process (Bradbeer, 1996), in particular in the last 25 years during which more critical reflection has come to be built into pedagogic structures (Dummer, Cook, Parker, Barrett, \& Hull, 2008). Evidence suggests that field learning may be retained longer, because there are opportunities for affective learning moments: emotions are tied to intellectual discoveries (Farmer, Knapp, and Benton (2007). But the social nature and culture of the residential field course is also important - students value activities when they can control and influence learning outcome. They appreciate the novelty of being in a new place, and the experience of doing practical work with peers and academics, away from the classroom, laboratory or formal teaching space (Simm \& Marvell, 2015 ). As such, the social experience of a field course is often reported as important in surveys of student satisfaction and the student experience, and has formed a central part of the marketing narrative of university geography programmes for at least 20 years (McEwen, 1996). The field can be fun, and fun can be useful for institutions as well as for students. Recent innovation has explored the potential of more "playful" ways of carrying out field investigation that explicitly stress the importance of creativity and a more open ended exploration, instead of the normative practice of skills (Lammes \& Perkins, 2016; Phillips, 2015). Our approach to this context is grounded in critical ludic studies from Raessens (2006), who argued that contemporary cultures are experiencing a ludic turn. We highlight particular aspects of play as being significant in a field context. Sutton-Smith (2001) argued play is ambiguous, multifaceted, embodies different rhetorical forms but above all else is social in its different forms and this focus echoes our approach to the field course. Sicart (2014) argued that play is beyond games, characteristic of being human, and a part of daily life, and that playfulness allows play to be deployed beyond its usual contexts, and we explore the extent to which kite mapping as "field play" might be a useful part of pedagogy. Our final playful influence is the work of psychologist Csikszentmihalyi (1990), whose notion of flow highlights key aspects of the creative potential that emerges during play.

To summarize: the literature suggests there are clear benefits for students from field experience which centre on the intellectual, technical and personal aspects of the experience and also that a more playful approach can impact in a positive way on field pedagogy.

\section{Mapping and field-work}

Mapping in this context has largely been reported as contributing to the development of technical skills (see for example Chatel \& Falk, 2017; Favier \& van der Schee, 2009; Kerski, 2015; Marra, van de Grint, Alberti, \& Karssenberg, 2017; Maskall \& Stokes, 2008). Maps have been used as part of the field experience - sometimes as a data source, sometimes as a base against which to plot information, and sometimes as a tool to use to navigate around the novel field environment (Muehrcke, 1972). The creation of specialist maps for specific disciplines still depends strongly upon field investigation, notably geological maps (see Lisle, Brabham, \& Barnes, 2011) and geomorphological maps (see Smith, 
Paron, \& Griffiths, 2011 ). Mapping can also play an important role in ethnographic field research (Andrews, 2012).

Map skill acquisition has frequently been taught in the field and sometimes evaluated as part of a wider appreciation of problem-solving (Riggs, Lieder, \& Balliet, 2009). Maps are used as means of graphically depicting the field when writing up research results, and in order to explain spatial relationships to others. In addition, field-courses have involved making maps, both by surveying the field and collecting information, and by annotating published maps with the information collected. Until recently this kind of map-related fieldwork almost always treated mapping as a technical activity, to be deployed as a tool amongst other research methods. There has indeed been a proliferation of recent papers about the contribution that different technologies might bring to geography fieldwork, whether it be GIS, GPS, smartphones, tablets, map-based storytelling, apps or geogames. Of direct relevance to our research has been the recent upsurge in interest in the capture of remotely sensed data using drones and other Unmanned Aerial Vehicles (UAVs) (Birtchnell \& Gibson, 2015; Jahn, Haspel, \& Siegmund, 2011; Jordan, 2015; Williams, Tooth, \& Gibson, 2017). However, little published literature has to date evaluated the potential of very low-cost aerial data capture, and kite-mapping in particular for consequent map making - apart from Sander (2014) whose ground-breaking paper is an essential starting point for any innovation in this area.

Wider disciplinary use of the map has recently been explored by Brunn and Dodge (2017). However, within geography (the archetypal field discipline), it has been recognized that human geographers in particular in the last 30 years have retreated from using maps in their work, at the very time when technology has led to a proliferation of map-use more widely in society, and specifically by researchers concerned with Geographic Information Science (Dodge \& Perkins, 2008). Recent trends in the deployment of mapping in field work have, however, started to emphasize the processes involved in mapping as an activity, instead of regarding it as a neutral tool to be used by field researchers. This changing emphasis draws attention to the different kinds of mapping on offer, and shifts attention to the everyday uses of mapping, recognizing that cartography has the capacity to strongly influence how people act in the field, and also to impact on the kind of research and learning outcomes that stem from field-work. As such a turn towards more "playful” mapping is happening (The Playful Mapping Collective, 2016), and our kite-mapping experiments were set up in that context.

Mapping exercises, during which they collect their own aerial images and interpret them, give students experience of using technical instruments, data collection, data analysis, and interpretation all critical career skills (Jordan, 2015) which chime with Sander's (2014) enumeration of the benefits of kite-mapping. However, we argue that much more than a technical consideration is needed in order to evaluate the potential of this mapping technique. There are broader potential benefits which stem from how the mapping is carried out. Hefferan, Heywood, and Ritter (2002) suggest that practical experience of "learning-by-doing" is an important feature of student learning during field experiences, and 
recognize that if students are given the opportunity of participating in a field-course, these practical opportunities can transform an average classroom student into a field scientist. The curricular framing in which mapping is deployed also strongly influences what students gain from the experience - in other words kite-mapping is received differently depending on how the activity relates to other elements of a field programme. This might include such variable factors as the sequence in which a workshop is delivered, the timing, the size of the group, the extent of instructor intervention, and how the mapping activity is assessed. The inclusion of reflection on the experience also significantly changes what has been learnt (Dummer et al., 2008). Lastly and critically published evidence suggests that field-based learning is an affective experience - when students feel most strongly about a learning style or a place they are more likely to remember the place, the experience and even the skills acquired during the fieldwork (Simm \& Marvell, 2015). So, embedding fun and creativity into a mapping experience is potentially a crucial part of the learning experience.

\section{Study area and equipment}

In this experiment, kite-mapping workshops were organized during two international multidisciplinary field-trips held in May 2016 and May 2017 on the island of Gozo, in the Maltese archipelago. Each year a group of 35 students, from five universities across four countries, came to explore different aspects of the island in interdisciplinary groups, using a range of "playful" methodologies. Activities were organized to encourage students to develop their own research themes, bringing together skills from their very different discipline areas, which ranged from human geography to development studies, GIS, game studies, interdisciplinary methods, and new media studies. During the field courses a total of twenty-one research themes were explored and included: hunting in Gozo: semiotics of Gozitan island identity; sacred space; feelings of security; historical tourism; surveillance; food and drink; Gozitan myth and legends; and water resources. Other aspects of these programmes are

AQ3 described elsewhere, notably a location-based game (HIDDEN FOR REVIEW), and a dérive-like exploratory mapping exercise (HIDDEN FOR REVIEW). The kite-mapping took place as one of three, parallel, sensory-mapping workshops designed to allow students to compare mapping approaches deploying different sensory modalities. Only about one third of all students selected the kite-mapping, the others preferred one of the other two workshops focused on smell mapping (McLean, 2015; Quercia, Schifanella, Aiello, \& McLean, 2015) and sound mapping (Gill, Grabarczyk, Baker, Naghshineh, \& Vonhof, 2017; Kang \& Schulte-Fortkamp, 2015 ).

The combination of sensory data gathered via these three workshops allowed students to explore the diversity of sensory modalities in relation to their research themes. Students had the opportunity to deploy kite aerial photography in the area of Xlendi Bay on the south-western coast of Gozo - see Figure 1). This area was chosen as it offered relatively easy access and had few obstructions that would interfere with kite flying, such as buildings or power lines. As a coastal area, it comprised flat limestone 
pavements, scrubby vegetation, cliffs and wave-cut platforms. Furthermore the steady winds assured the highest probability of successful flights and thus the mapping activity.

Figure 1. Kite mapping Site in Xlendi Bay, Gozo (Malta).

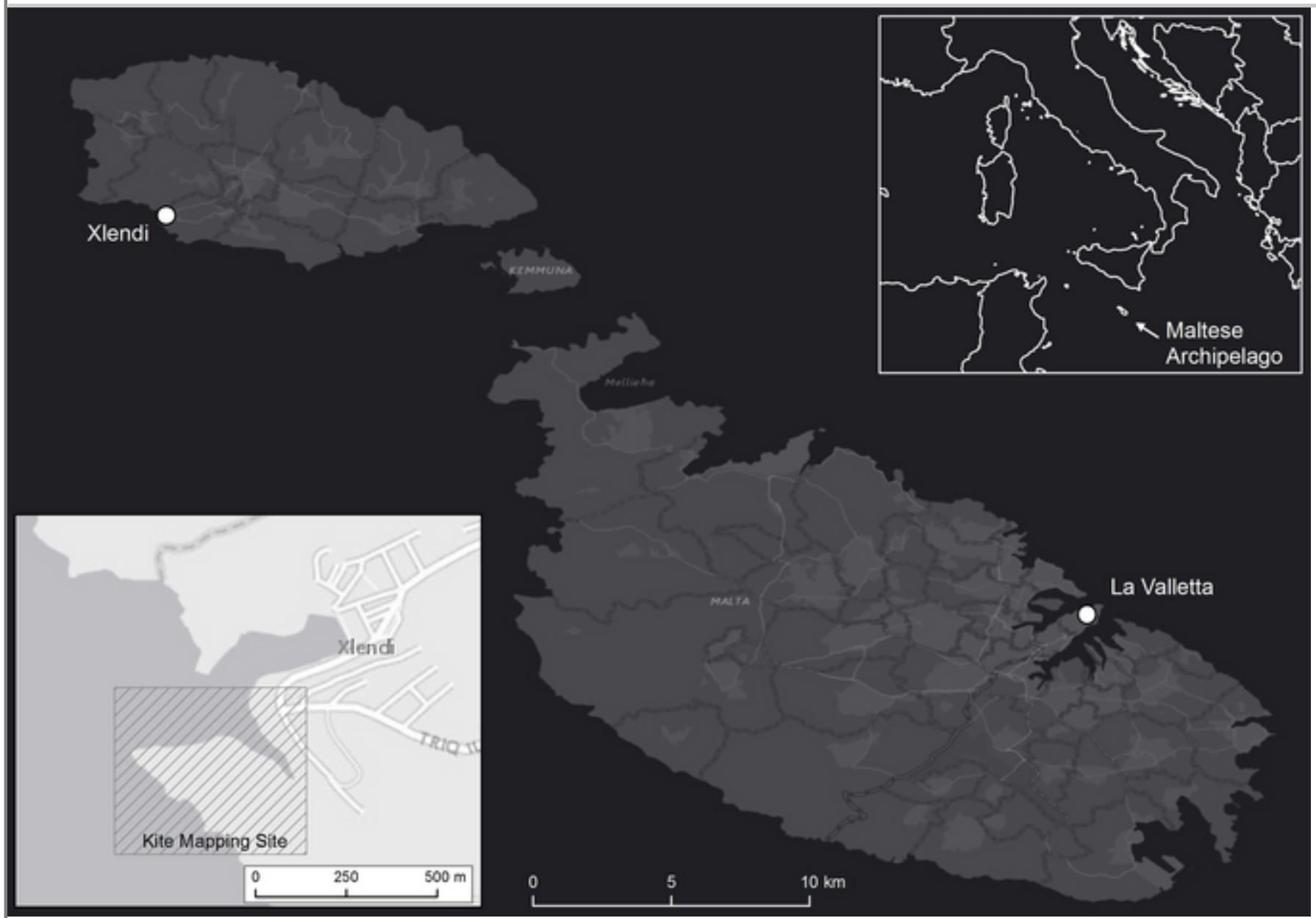

Basemap sources: ESRI 2013, HERE, DeLorme, MapmyIndia, NAVTEQ, OpenStreetMap contributors, and GIS user community, thematicmapping.org.

Kite Aerial Photography is a low-cost and do-it-yourself alternative to expensive (100\$ kitemapping set) and restricted aircraft mapping and the use of drones, and offers significant potential advantages for field use (Sander, 2014). A typical combination of a kite, camera and an operator characterizes most cited examples of the technique. The students had access to seven-foot (useful for stronger winds and lighter cameras) and nine-foot delta kites (which were easier to fly and more suitable for lighter winds) available from PublicLab.org Store (Public Lab, 2013 ). Three Canon cameras (PowerShot A2500, PowerShot A480 and PowerShot A2300) were available and were accompanied by the Canon Hack Development Kit (CHDK) intervalometer script (CHDK Wikia, 2007). The CHDK is a free, temporary and experimental toolkit that allows users to modify their Canon camera firmware. In this case, cameras were turned into continuous shutter mode taking pictures every two seconds, whilst maintaining automatic focus, white balance, aperture and shutter speed. The photographs were saved in JPEG format at the highest quality available on each camera. 
The resolution of seamless images created from kite aerial photography is usually high (Aber \& Aber, 2003 ), often with average spatial resolution better than $5 \mathrm{~cm}$ (Currier, 2015). Resolution depends upon the focal length and other qualities of the camera lens, and the altitude at which a kite flies. In comparison, high-resolution satellite imagery provided by Google Earth or Bing Maps with a sub-meter resolution is poor quality and may be less appropriate for this type of participatory mapping. Some services/satellites offer professional imagery free-of-charge, e.g. Sentinel 2 from European Space Agency, or Landsat 8 operated by National Aeronautics and Space Administration, but with spatial resolution of 10 meters per pixel (ESA, 2017), or 30 meters per pixel (NASA, 2017), respectively. On the other hand professional sources such as WorldView offer high resolution on demand images, but their price-range is not suitable for geography field courses.

Beside kites, other platforms could have been used for small area aerial mapping, such as unmanned aircraft systems (UASs), balloons or poles. In areas where stable wind conditions are rare, helium-filled balloons have sometimes been used as an alternative to kites in order to lift cameras. This is often seen in urban areas such as Lima, Peru (Warren, 2010), where streams of wind are disrupted by urban landmarks or street layouts. Kites, however, offer particular advantages in the mapping of coastal areas which can be too windy and unsafe for a drone to be flown, demonstrating the important complementary role of kite platforms in data capture. Kites can also be used at higher altitudes than pole-based systems, and are not legally restricted, unlike highly regulated UAVs (Duffy \& Anderson, 2016 ). Although drones often offer better spatial resolution and camera qualities than kites, the costs involved in purchasing, transporting, and operating drones, together with legal restrictions exclude wider deployment of drones from most geographical field-trips. In our case the conditions at the Xlendi coastal site were too windy and unsafe to allow a drone or helium-filled balloon to be flown, therefore kites were selected as the optimal remote sensing device. Another reason for selecting kites was the possibility of replacing parts in the event of damage - for example due to the unexpected wind conditions. Aerial mapping from kites would we felt be unlikely to impede field-course workflow, whereas drones, were not replaceable using DIY methods in the field. Moreover, the experiential aspects of flying a kite (e.g. students create necessary amenities before they actually fly a kite; process of installing a camera itself and consequent attachment to a kite; carrying the whole equipment to a mapping area; and preparing a kite for the flight) represent unique in-the-field learning outcome for the participating students.

The kites were controlled via $305 \mathrm{~m}$ Dacron (polyethylene terephthalate) line insert "line (see Figure 2)". ... Cameras were attached 10 meters below the kites where they sat in a cradle which the student groups themselves constructed during a preparatory phase of the workshop (Figure 2 Change AQ4 to "Figure 3" ...). 


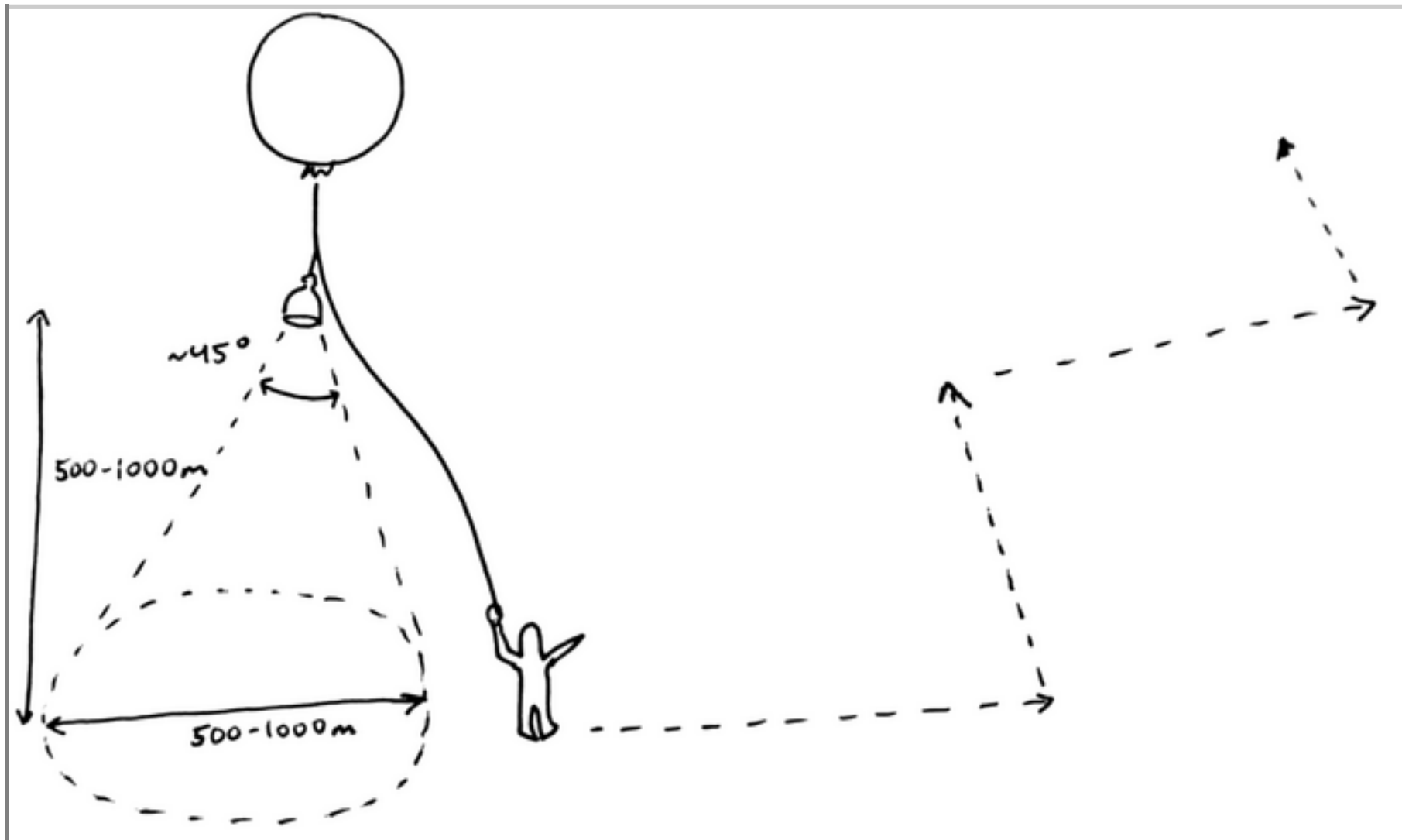

(Image source: Grassrootsmapping.org, 2010).

\section{Workshop phases}

The sensory mapping days, during which the kite-mapping workshop took place was scheduled for day three or day four of a 10-day field-course. Participating students already knew each other - they had opted to take part in kite-mapping instead of one of the other parallel sessions. Students themselves chose who to work with. The workshops were divided into three sections: building the mapping kit, mapping in the field, and data post-processing. Each of these segments lasted approximately 3-4 h.

\section{Building the mapping kit}

During the first phase of the workshop, students were tasked with making a cradle for the camera that could be attached to the kite and would carry the camera in an orthogonal position, protecting it to some extent when the kite would fall. They were given cardboard boxes, plastic bottles, sticky tape, scissors and other office equipment. This group exercise resulted in many different and creative designs with different functionalities, and this DIY ethos reflected the student-led, group-based ethos of the field course (see Figure 3). It rapidly emerged that the design of a case and the material used in its construction later played a crucial role during the "lift-off" of a kite (Figure 4). Plastic bottles are lighter and thus easier to fly compared to cardboard boxes, but some types of cameras did not fit into the plastic bottles available (ordinarily up to $10 \mathrm{~cm}$ diameter near the necks of the bottles). When using a cardboard box, the main disadvantage lay in achieving a perfect fit for the camera in the box, intended to prevent it from moving during flight (see the problem in Figure 5(a)). 
Figure 3. Examples of student-built camera cases attached to the kite.

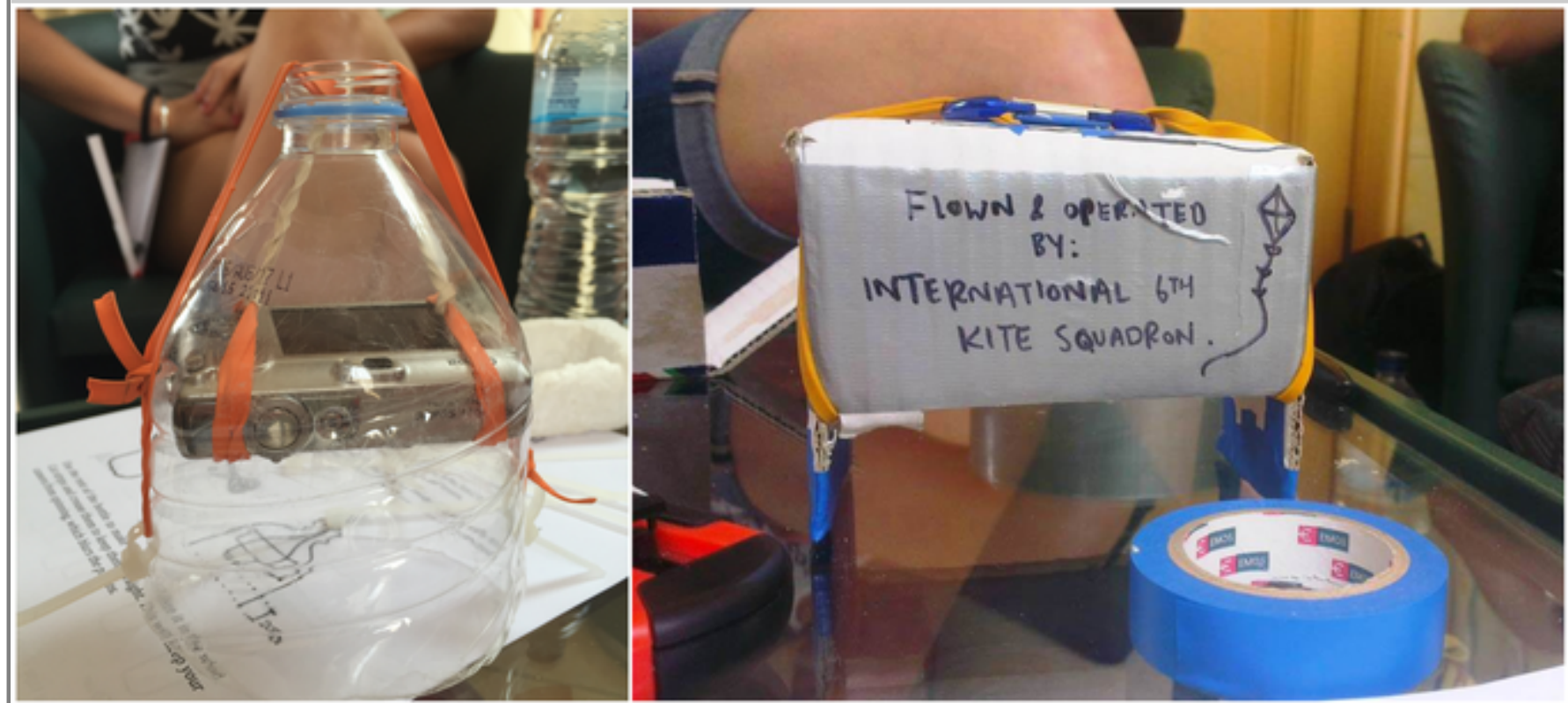

Figure 4. Kite mapping activity at Xlendi.

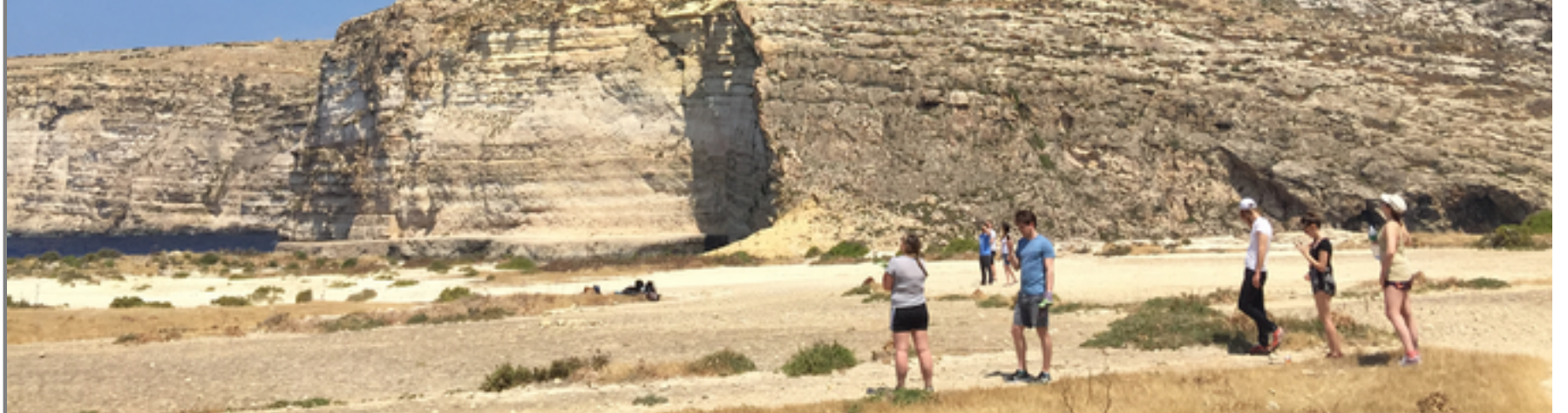


Figure 5. Examples of pictures taken from a kite, (a) unsuitable for processing (part of a case caught by camera, and control line captured), (b) unsuitable oblique picture, (c) unsuitable orthogonal blurred picture, (d) orthogonal sharp picture suitable for stitching in MapKnitter environment.
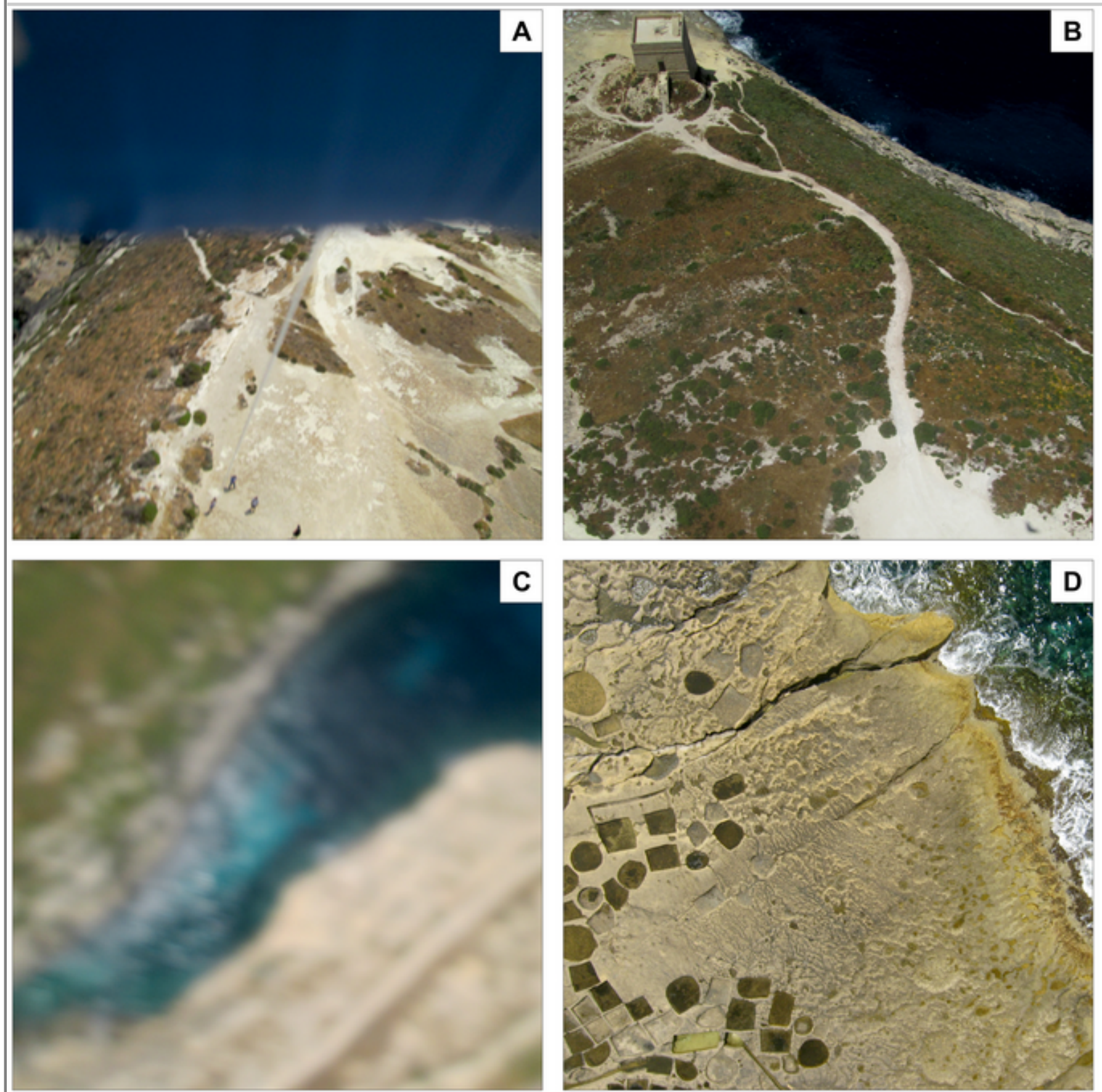

\section{Mapping in the field}

After finishing the camera case, the students learnt how to fly a kite, first without the camera and then with the camera. The additional weight of the camera and cradle made it harder to lift the kite and required stronger wind, but once in the air, the kites flew easily. Students were encouraged to select different areas distributed along the coast line, so each group would map a different part of the coast. Each group had four or five members, as we had only three kites available for the first year and four kites for the second year. At least two students were needed to operate each kite, so the group size was 
big enough for everyone to take a turn to fly a kite. The mapping itself took about one hour and comprised of several flights separated by short breaks to check the quality of photos, camera battery life and remaining space on SD cards in the cameras. The kites were flown at heights between 50 and 200 metres depending on the wind. The maximum theoretical height was limited by the length of the control line $(305 \mathrm{~m})$, but that length would have required absolute orthogonal positioning of the kite above the operator, which is practically impossible.

In order to map larger areas, once the kites had reached a stable flying altitude, students were encouraged to walk along the coast pulling the kite against the wind. Similar techniques are often used when kites are dragged behind boats, for example when mapping sea water quality (Breen, Dosemagen, Warren, \& Lippincott, 2015) or penguin colonies (Fraser et al., 1999). Amongst the most important practical lesson learnt by students in our two workshops was the need to always be in control of their kites. Any sudden drop in the strength of the wind, or change in the wind direction would potentially cause the kite to fall to ground. During the second workshop, one group let their kite fly at its maximum altitude, using the whole control line, but suddenly the wind ceased to blow and the kite plummeted straight down into the sea: too much slack in the line prevented intervention to save the kit. It was impossible to roll $300 \mathrm{~m}$ of line back to the operator in time to impact on the kite trajectory.

Fortunately, the data from the SD card was rescued. Another important practical lesson learnt in the first workshop was to devise a sampling strategy that prevented groups overlapping or meeting. Tangling kite lines is also a recipe for grounding!

\section{Data post-processing}

Post-processing of data was divided into three stages (1) image selection; (2) image stitching; (3) creating a final map. This phase required significant input from staff, and students found it harder to all participate in what was a much more individual activity. In practice, one or two people in each group concentrated on selection, stitching and map making.

The selection of best images was the crucial and very often took longest, as during the mapping activity each group captured about 1000 pictures per flight. Only 20 to 30 of these images were needed to create a seamless mosaic of the coast. The ideal images were sharp, orthogonal and without any object between the camera and the surface. In Figure 5, which shows four of the most common examples of pictures taken from a kite, three of the four images (Figure 5(a)-(c)) are not suitable for further processing.

Once the best pictures were selected, they were stitched together using the web based open-source software MapKnitter. This software allows users to upload an image, rotate, distort and stretch it onto a reference map, and use the transparency and outline modes to check how close the fit is. Students were then able to export the final image to GeoTIFF or OpenLayers/TMS. It was important that images included some easily recognizable feature such as a road, building or a cliff edge. If the picture only 
showed sea, scrubby vegetation, or a featureless piece of wave-cut platform it would be too difficult to place it on the map, as no common reference points could be identified. Features such as the cliff edge, or former salt pans, by way of contrast, were much easier to locate and identify. Once all the images were located and stitched, students used MapKnitter to export seamless image in one of the preferred file formats, mostly GeoTIFFs. MapKnitter uses Google Maps as a background against which images can be overlain while stitching - this helps with georeferencing the final product and GeoTIFFs can subsequently be used regardless the background data. There were no difficulties in stitching the picture into one seamless mosaic, since the tool is intuitive and students did not need any specialized background in cartography, or GIScience. However, this activity was not deemed as exciting as the social novelty of kite flying (Figure 6).

Figure 6. Post-processing phase - (a) MapKnitter user interface, (b) exported GeoTIFF.

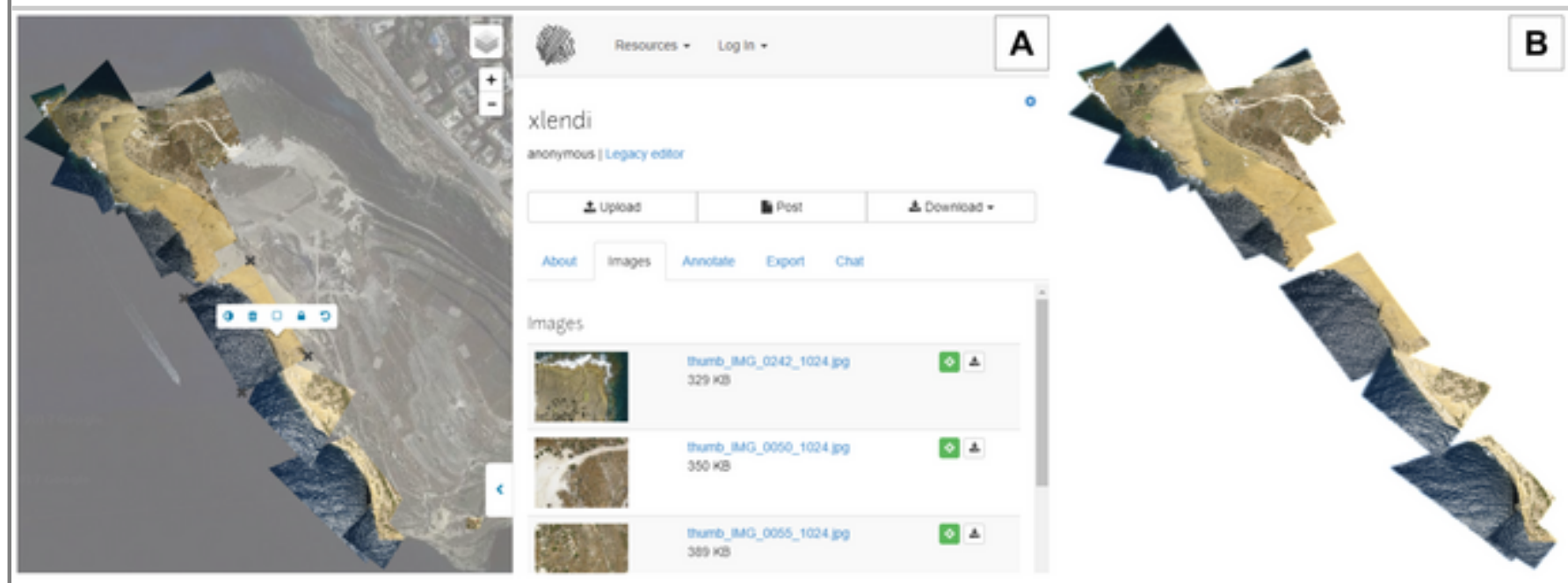

In theory students were able to work in any GIS software to manipulate the seamless image. During the workshop we used the open-source multi-platform software QGIS with the OpenLayers plug-in. This allowed students to add Web Map Service (WMS) tiles such as OpenStreetMap or Google Maps as an additional background. In QGIS students were able to create maps insert "(Figure 7)." behind word maps ,.., but also to identify locations that were useful for further research during the field-course, such as situating hunting sites, or locating watch towers. During map making, the differing student disciplinary backgrounds were much more significant than in earlier phases. Frequently technical support was needed from staff, in the form of additional information about coordinate systems, WMS services, data formats, basic cartographic rules, and the QGIS environment itself. More guidance beyond the scope of a handout was needed to help some groups (Figure-7). 


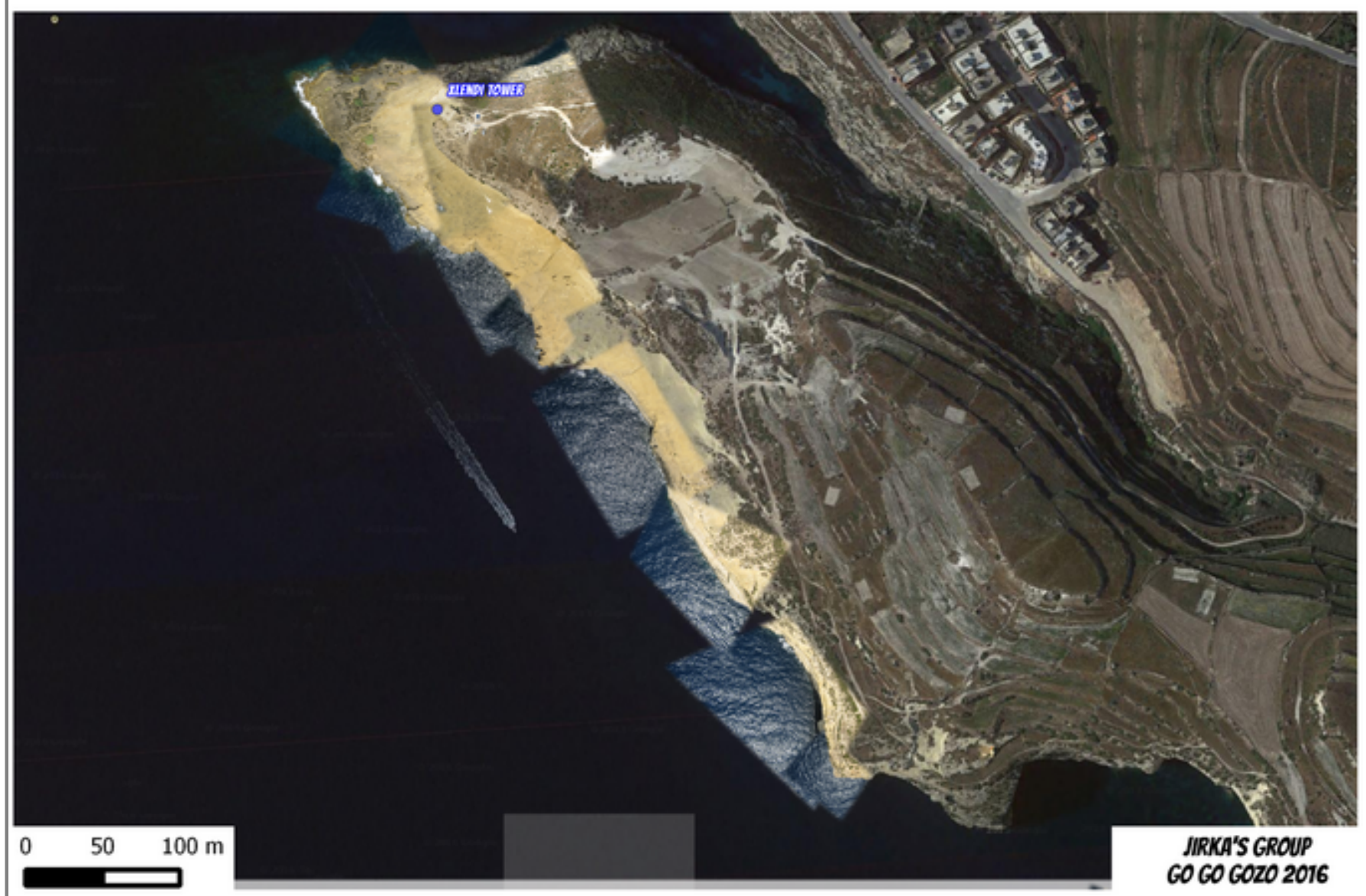

Basemap source: Google, Inc.

\section{Evaluative methods}

Evaluation of the kite mapping was carried out using a mixed methodology incorporating staff and student views, before, during and after the workshops. Staff observed field practice during the different phases of the exercise and were able to compare this to field briefings, previous mapping workshops, and to other published work. Student views of the innovation were assessed by drawing on individual reflective diaries kept by students in each year of the programme, and by discussing their results after the completion of the mapping. In addition a post hoc online evaluation was carried out with students who took part in the workshop. The post hoc survey generated 23 different responses to the questionnaires. There were slightly more female students who took part in the workshop evaluation (13), as against 10 male students. They came from four of the five universities that took part in the field-course with 16 students from the University of Manchester, four from Palacký University

Olomouc, two from the University of Warwick and one from Utrecht University. Students were from various disciplinary backgrounds, but most from geography (15), followed by international development studies (3), digital media and culture (3) and visual anthropology (1). Only one had any prior experience with kite mapping. The evaluation had three questions regarding the "playfulness" of the process and related to the three stages of workshop, and one question related to the usefulness for geography in higher education. At the end of the survey students could comment on their answers. As 
such we drew on multiple viewpoints, with respondents from each discipline area, and deployed a mix of quantitative and qualitative approaches. Our evaluative strategy does not directly compare our kite mapping workshops with other ways of collecting remotely sensed data in the field, but it does explore student perceptions from participants with different backgrounds and attitudes towards scientific data collection, and it does explore differences in conceptual learning evidenced in this process. The evaluation presented below combines answers from two years of the field-course and draws on these different sources of information.

\section{Discussion}

The workshops piloted in 2016 and 2017 clearly explored several aspects of best practice and also revealed examples of practices that should be avoided in the future. There are plenty of success stories published about kite-mapping (see Anderson et al., 2016; Breen et al., 2015; Bryson et al., 2013; Currier, 2015; Duffy \& Anderson, 2016), but a more rounded recognition of failures as well as successes is frequently absent in published evaluations. From our evaluations a number of generalizations (both negative and positive) can be made relating to technical and skill related issues, but also to broader pedagogic and philosophical issues around learning and the performance of mapping in the field.

\section{Skills and technical issues}

In both years the workshops were successful in terms of getting the kites into the air, acquiring pictures and stitching them together in a seamless image, that could later be used as a backdrop image in GIS software. The ability to create their own map from scratch in a day was highly appreciated by both students (and evidenced in their methodological reflections), and the workshop organizers. Both groups evidently learnt from doing (Hefferan et al., 2002). From the qualitative student methodological reflections it is apparent that students all engaged very strongly with the technique. They clearly enhanced their geographical and remote-sensing skills by actively mapping in a real world context and their methodological reflections strongly evidence their appreciation of the different stages that were involved in the exercise "because it allows you to get a deeper understanding for how aerial maps are made, and also gives you a way around obtaining data that may not be otherwise accessible" (survey respondent 2017). This finding certainly gels with Sander's (2014) results.

Staff also reflected on the relative ease with which student groups engaged with the different stages of the process and the relative lack of staff time guiding participants. This was predominantly a studentled, research-based activity (Healey, 2005). There were mixed responses to the group-based, cradlemaking phase. Whilst the majority of those completing the survey appreciated the creative and problem solving activities that were brought into play, ("I wasn't a geographer anymore, I was an engineer with a masters in sandcastles and a PhD in Lego" (Student reflection C 2016)) and the compatibility with a DIY mapping ethos, a minority of students felt marginalized by the amateur and craft process. The 
social activity of kite flying was, however, unsurprisingly very popular - every one of the 15 methodological reflections reported enjoying that phase of the exercise, and 21 of the 23 surveys reported this as a strongly playful element of the programme. The final, more technical, phase of postprocessing of data was also evaluated positively, but there is a clear difference between the first two parts of the workshop and the last one. Post-processing was often very time-consuming and was not as creative as building the case and flying the kite - groups with images capturing a cradle instead of a view to earth needed to spend large amounts of time editing material - which was not as pleasurable as reverting to childhood and flying a kite! Nevertheless, it was the post-processing that arguably had the highest educational value as it brought all the previous experience and knowledge together and allowed practical links to be made to transferable GI and mapping skills.

Students also appreciated the nature of kite mapping beyond the immediate skills involved in the map-making itself. They recognized the bottom-up nature of the activity (Currier, 2015) and its potential to generate very low cost data. They made the links to other contexts where a participatory mapping approach might require an affordable but high-quality outcome, such as the rapid mapping of a humanitarian crisis, or a citizen science-based data-collection exercise, or developing world applications. For example, one respondent wrote "It's low cost, allows mapping in developing regions and is accessible to undergraduates" (Survey 2016). So affordable availability was recognized as an important aspect of the approach. Students were also very aware of their position vis-a-vis the data: the fact they had made the maps in the field was important to them. Their ownership over the mapping was appreciated. In the words of one survey respondent from 2016, "creating a map that is entirely yours..." makes a difference, and this contrasted strongly with the distance and apparent authority of the Google Map against which we suggested they drape their images. One participant (Student A reflection 2017) reacted very critically to using Google imagery to reference their own mapping: "I was almost disappointed .... If we were just going to use Google Maps to compare our images to". Students were also surprised how easy it was to gain very high resolution data. They recognized that simplicity was an important part of the exercise: "I now understand the scope of benefits that can come from using such a simple device" (Survey response 2016). Nevertheless it is important to stress, that height, tilt and camera distortions were not introduced as it would make the whole stitching process much more complicated. The field-course was not focused on remote sensing, hence the simplification of the aerial images processing was implied.

In addition to perceptions of success there were also frequent references in student evaluations to failures. Probably the most unstable component of kite mapping is the weather, as kites are strongly dependent on stable, fairly strong winds, with a minimum of $15 \mathrm{~km} / \mathrm{h}$ and from a consistent direction. For our flights we used the WindGuru (2016) webpage which among other variables provides wind speed, gusts and direction. When the wind is not strong enough the kite will not fly, or will fly only without the camera, but once the camera is attached the kite becomes too heavy to be lifted by the wind. 
But in very strong wind the kite becomes uncontrollable and there is a risk that the line that operates the kite will break. Unlike the strength, the direction of the wind is not that crucial for successful flight, but if it is raining the kite becomes heavier and flying is also impossible. Hence, proper planning with frequent checking of weather forecasts is crucial for successful flights. Only a single day in the 2016 field course has suitable conditions.

Another element that affected our flights was the ability to operate the kites properly. Although students could practice flying the kite without the cameras prior to the mapping activity, we experienced several groundings, in particular in 2017, in which kites and cameras fell to earth or water. The cradles mostly protected the cameras well, but two cameras were destroyed during two years of the fieldcourse. One camera was crushed in a precipitous fall onto the cliffs, and a second drowned as one kite fell into the sea. In both cases the SD cards with pictures were retrieved, but both cameras were lost. As we did not have backup cameras, the loss of the device meant the end of the workshop for that group. Therefore, at least one reserve camera should be available for use, as kite-crashes may occur anytime during the exercise. Students were inevitably frustrated by this failure: "I found sometimes frustrating when our kite didn't want to fly or when we destroyed cameras" (Survey, 2017). Although two low-cost cameras were lost, the total price for the workshop was still lower than the cost of any UAV available at that time.

Others saw the exercise as at best marginal to a chosen research theme. Whilst the approach clearly directly informed a 2016 group researching hunting, affording a birds-eye view of the landscape, it was seen as largely irrelevant by a 2017 group researching socially mediated tourism. This failure was, however, in many cases a productive opportunity to reflect on other aspects of research practice. Student A in 2017 used the kite mapping exercise to "feel the terrain" - by walking with the kite, he gained a different impression of the landscape.

\section{Wider issues relating to pedagogy and mapping}

Student reflections often appreciated the difference that mapping technologies brought to methods and to knowledge creation. By making their own maps, they came to realize the visual power of the medium, and the capacity of the birds-eye view to appear to show everything, conveying a God-like command over the landscape (Haraway, 1988). For some, the use of kites as a technology (as against a UAV as a technology) made this objectifying more problematic. Student B in 2016 commented "the kite and its operator are connected, there's a visibility that manifests trust, contrary to drone technologies, where the human involvement is often detached invisible, unnerving". She used this insight to think differently about the ethics of capturing photographic images during ethnographic photo-elicitation later in the field course. Kite mapping allows you to see the links between the technology, the researcher and the world, and in so doing helps you to think more critically about scientific practice. A participant in 2017 (Student D) recognized the capacity of the kite -mapping images to freeze time, and as such to 
facilitate comparisons and appreciate processes, but also to reflect on the ethics of geolocating photographic images, which in so doing reveal the private to a wider audience. He used this observation to think through power imbalances between researchers in control of the camera, and "subjects" captured by the lens. Seeing at a distance from a kite might reveal actions regarded as private by someone captured in the image, and resolution is clearly sufficient to identify people who are unlikely to have given permission to be included. So the ethical issues in kite mapping are important and the capacity of the remotely sensed image to witness an event is crucial (see Parks, 2001). These links across the field curriculum show that a wider reflection on the technique can usefully inform other field practice. During the feedback session in 2017 we invited participants in each of the sensory days to reflect on the differences between sight, sound and smell as sensory modalities in fieldwork (see Phillips, 2015 ). Student observations evidence that their experience of kite -mapping practice was strongly critical. It was much more than a data -collection technique for almost every student, and even during failure facilitated subsequent insights into other field pursuits.

Reflection on kite-mapping showed an often deep appreciation of the place of the technique in relation to the wider ethos of the field programme. A playful approach to learning was one of the main research aims of the whole field programme and of the Strategic Partnership on which it was based (see HIDDEN FOR REVIEW). The ability to play with the map and to play during map making can result in a forgiveness towards mistakes, and a more open approach towards methodological innovation that is rare in other educational settings and should be encouraged (The Playful Mapping Collective, 2016 ). As such, our approach to kite-mapping invited critique, and saw the "results" as very much provisional, in line with a processual view of mapping as called into being with affordances designed to achieve certain tasks (Kitchin \& Dodge, 2007). Students recognized the partial-knowledge claims that this approach invoked and were sanguine about the power of the technique. They regarded its success as very much a reflection of their own participation in creative map making. Student $\mathrm{C}$ in 2016 regarded kite mapping as "the best day I've had during my university career", Student E in the same year suggested she found the method "extremely pleasurable" and "easy to engage with". It is the affective power of the mapping that leads to many of the insights, rather than just the skills that it allows students to practice - and the playful ethos of the workshops played an important part in their successes and failures, as in many field encounters with place (Simm \& Marvell, 2015).

Students went beyond the workshop and explored the method on their own terms. Some attached their own GoPro cameras on kites in order to tape videos or take pictures additional to Canon cameras with CHDK scripts. Although the waterproofness and durability of GoPro cameras can seem as an advantage, the fish-eye like lens distorts the images too much (see Figure 8 ) so they are hard to use for post-processing and stitching. Nevertheless these outdoor sport cameras may provide interesting overviews of the area and the videos captured during the flight may bring additional sensory (audio) 
information and experience from the flight. It is the affective power of kite-mapping (see Craine \& Aitken, 2009) that encouraged this active intervention.

Figure 8. GoPro camera image of the Xlendi bay, Photo by: Alastair Gourley, 2016 participant.

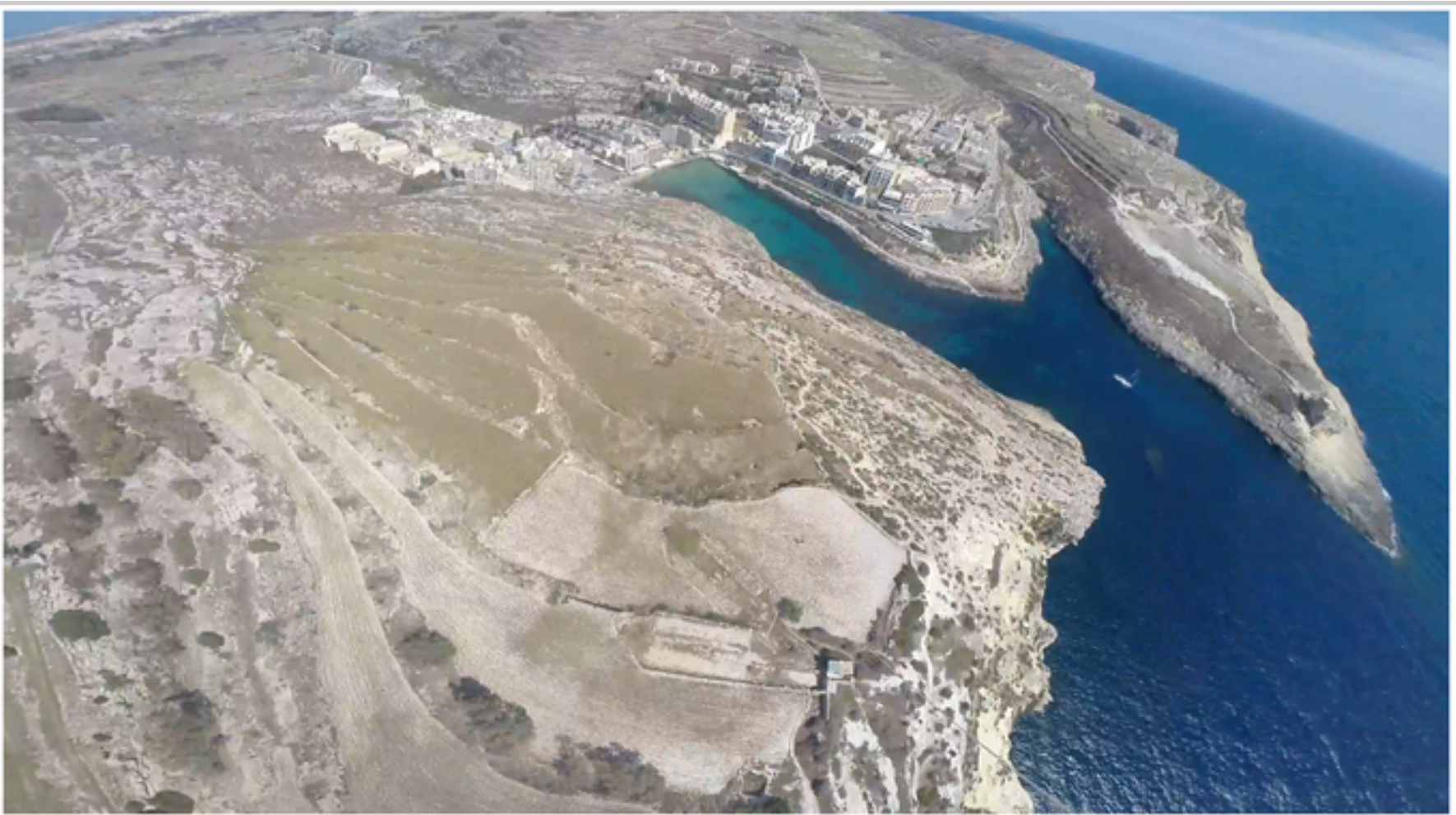

\section{Conclusion}

Duffy and Anderson (2016) regard kites as one of the earliest proximal sensing vehicles for scientific studies, and argue they may be set to be a key part of the modern geographer's toolkit. We would not go this far, but our evidence certainly shows that kite-mapping does indeed deliver low-tech and potentially open-source data to offer a complementary and, in some cases, better platform for proximal remote sensing than UAVs. Their observations were partly supported in our field-testing of kite-mapping, as well by our multiple methods of assessing staff and student views of the two workshops. In line with Sander's work (2014) the kite-mapping activity proved to be a valuable component of the field-course as it provided students with insights into several aspects of geography and GIScience, from elementary remote sensing and basics of surveying to critical cartography and DIY citizen science. Their technical skills benefitted from the use of the technique in the field. Their methodological reflections also showed that they also appreciated the contribution the technique made to other parts of the field programme. However, our evaluation also reveals aspects of the process through which these insights emerged. We have suggested that deploying kite-mapping is probably really successful in a pedagogic context because of: its novelty for participants; as a practical, playful and creative methodology; because of the enjoyable social context in which it is deployed; and because of the sense of achievement emerging from the activity. We have highlighted perceptions of kite mapping and explored how these affective and experiential factors mattered during the playful Gozitan 
field encounters. As such, this paper is more than a manual for kite-mapping. It is an argument for more of a focus on how mapping methods are deployed, an exploration of processes enrolled into a more playful pedagogy, and a testimony to the authors and students in the multidisciplinary context who AQ5 participated in the kite-mapping workshops.

\section{Disclosure statement}

AQ6 No potential conflict of interest was reported by the authors.

\section{Funding}

This work was supported by the Directorate-General for Education and Culture [grant number 2014AQ7 1-UK01-KA203-001642].

\section{References}

Aber, J. S. , \& Aber, S. W. (2003). Applications of kite aerial photography: Property survey. Transactions of the Kansas Academy of Science, 106(1 \& 2), 107-110. doi:10.1660/0022AQ8 8443(2003)106[0107:AOKAPP]2.0.CO;2

Aber, J. S. , Aber, S. W. , Pavri , F. , Volkova , E. , \& Penner, R. L. (2006). Small-format aerial photography for assessing change in wetland vegetation, Cheyenne Bottoms, Kansas. Transactions of the Kansas Academy of Science, 109(1 \& 2), 47-57. doi:10.1660/00228443(2006)109[47:SAPFAC]2.0.CO;2

Aber, J. S. , Eberts , D. , \& Aber , S. W. (2005). Applications of kite aerial photography: Biocontrol of salt cedar (Tamarix) in the western United States. Transactions of the Kansas Academy of Science, 108(1 \& 2), 63-66. doi:10.1660/0022-8443(2005)108[0063:AOKAPB]2.0.CO;2

Aber , J. S. , \& Gałązka , D. (2000). Potential of kite aerial photography for Quaternary investigations in Poland. Geological Quarterly, 44(1), 33-38.

Anderson, K. , Griffiths , D. , DeBell , L. , Hancock , S. , Duffy , J. P. , Shutler , J. D. , \& ... Griffiths , A. (2016). A grassroots remote sensing toolkit using live coding, smartphones, kites and lightweight drones. PLOS One, 11(5), e0151564. doi:10.1371/journal.pone.0151564

Andrews , H. (2012). Mapping my way: Map-making and analysis in participant observation. In AQ9 Mapping cultures (pp. 216-236). Springer.

Birtchnell , T. , \& Gibson, C. (2015). Less talk more drone: Social research with UAVs. Journal of Geography in Higher Education, 39(1), 182-189.

Boike, J. , \& Yoshikawa, K. (2003). Mapping of periglacial geomorphology using kite/balloon aerial photography. Permafrost and Periglacial Processes, 14(1), 81-85.

Bradbeer, J. (1996). Problem-based learning and fieldwork: A better method of preparation? Journal of Geography in Higher Education, 20(1), 11-18. 
Breen , J. , Dosemagen , S. , Warren , J. , \& Lippincott , M. (2015). Mapping grassroots: Geodata and the structure of community-led open environmental science. ACME, 14(3), 849-873.

Brunn, S. D. , \& Dodge , M. (2017). Mapping across academia. Dordrecht: Springer.

Bryson, M. , Johnson-Roberson , M. , Murphy , R. J. , \& Bongiorno , D. (2013). Kite aerial photography for low-cost, ultra-high spatial resolution multi-spectral mapping of intertidal landscapes. PLoS One, 8(9), e73550. doi:10.1371/journal.pone.0073550

Chatel , A. , \& Falk , G. C. (2017). SmartGeo-Mobile learning in geography education. European Journal of Geography, 8(2), 153-165.

CHDK Wikia. (2007). UBASIC/Scripts: A simple intervalometer. Retrieved June 10, 2014, from http://chdk.wikia.com/wiki/UBASIC/Scripts:_A_Simple_Intervalometer

Craine , J. , \& Aitken, S. C. (2009). The emotional life of maps and other visual geographies. Rethinking Maps: New Frontiers in Cartographic Theory, 28, 149.

Csikszentmihalyi , M. (1990). Flow: The psychology of optimal experience. New York, NY: Harper and Row.

Currier, K. (2015). Mapping with strings attached: Kite aerial photography of Durai Island, Anambas Islands, Indonesia. Journal of Maps, 11(4), 589-597. doi:10.1080/17445647.2014.925839

de Beauffort, G. , \& Dusariez, M. (1995). Aerial photographs taken from a kite: Yesterday and today. Brussels: KAPWA-Foundation Pub.

Delord, K., Roudaut, G., Guinet, C., Barbraud, C., Bertrand, S. , \& Weimerskirch , H. (2015). Kite aerial photography: A low-cost method for monitoring seabird colonies. Journal of Field Ornithology, 86(2), 173-179. doi:10.1111/jofo.12100

Dodge , M. , \& Perkins , C. (2008). Reclaiming the map: British geography and ambivalent cartographic practice. Environment and Planning A, 40(6), 1271-1276.

Duffy , J. P. , \& Anderson, K. (2016). A 21st-century renaissance of kites as platforms for proximal sensing. Progress in Physical Geography, 40(2), 352-361. doi:10.1177/0309133316641810

Dummer, T. J. B., Cook, I. G., Parker, S. L. , Barrett, G. A. , \& Hull , A. P. (2008). Promoting and assessing "deep learning"in geography fieldwork: An evaluation of reflective field diaries. Journal of Geography in Higher Education, 32(3), 459-479.

ESA. (2017). Spatial - Resolutions - Sentinel-2. Retrieved December 4, 2017, from https://sentinel.esa.int/web/sentinel/user-guides/sentinel-2-msi/resolutions/spatial

Farmer , J. , Knapp , D. , \& Benton , G. M. (2007). An elementary school environmental education field trip: Long-term effects on ecological and environmental knowledge and attitude development. The 
Journal of Environmental Education, 38(3), 33-42.

Favier, T. , \& van der Schee, J. (2009). Learning geography by combining fieldwork with GIS. International Research in Geographical and Environmental Education, 18(4), 261-274.

Fraser, W. R. , Carlson, J. C. , Duley , P. A. , Holm , E. J. , \& Patterson , D. L. (1999). Using kitebased aerial photography for conducting Adelie penguin censuses in Antarctica. Waterbirds, 22(3), 435-440. doi:10.2307/1522120

Gill , S. A. , Grabarczyk , E. E. , Baker, K. M. , Naghshineh, K. , \& Vonhof, M. J. (2017).

Decomposing an urban soundscape to reveal patterns and drivers of variation in anthropogenic noise.

Science of The Total Environment, 599-600, 1191-1201. doi:10.1016/j.scitotenv.2017.04.229

Grassrootsmapping.org. (2010). An Illustrated Guide to Grassroots Mapping with Balloons and Kites. Retrieved from http://archive.publiclaboratory.org/download/Grassroots_Mapping_English_2_0.pdf

Haraway, D. (1988). Situated knowledges: The science question in feminism and the privilege of partial perspective. Feminist Studies, 14(3), 575. doi:10.2307/3178066

Healey, M. (2005). Linking research and teaching to benefit student learning. Journal of Geography in Higher Education, 29(2), 183-201.

Hefferan, K. P. , Heywood, N. C. , \& Ritter , M. E. (2002). Integrating field trips and classroom learning into a capstone undergraduate research experience. Journal of Geography, 101(5), 183-190.

Higgitt, M. (1996). Addressing the new agenda for fieldwork in higher education. Journal of Geography in Higher Education, 20(3), 391-398.

Jahn , M. , Haspel , M. , \& Siegmund, A. (2011). Glokal change: Geography meets remote sensing in the context of the education for sustainable development. European Journal of Geography, 2(2), 21-34.

Jordan , B. R. (2015). A bird's-eye view of geology: The use of micro drones/UAVs in geologic fieldwork and education. GSA Today, 25(7), 50-52.

Kang , J. , \& Schulte-Fortkamp , B. (2015). Soundscape and the built environment.

Kent, M. , Gilbertson, D. D. , \& Hunt , C. O. (1997). Fieldwork in geography teaching: A critical review of the literature and approaches. Journal of Geography in Higher Education, 21(3), 313-332.

Kerski , J. (2015). Geo-awareness, Geo-enablement, geotechnologies, citizen science, and storytelling: Geography on the world stage. Geography Compass, 9(1), 14-26.

Kitchin , R. , \& Dodge , M. (2007). Rethinking maps. Progress in Human Geography, 31(3), 331-344.

Lammes , S. , \& Perkins, C. (2016). An introduction to playful mapping in the digital age. In The Playful Mapping Collective (Ed.), Playful mapping: Playing with maps in contemporary media cultures 
(pp. 12-27). Amsterdam: Institute for Network Culture.

Lisle , R. J. , Brabham, P. , \& Barnes , J. W. (2011). Basic geological mapping (Vol. 42). Chichester: Wiley.

Marra, W. A., van de Grint, L. , Alberti , K. , \& Karssenberg, D. (2017). Using GIS in an Earth Sciences field course for quantitative exploration, data management and digital mapping. Journal of Geography in Higher Education, 41(2), 213-229.

Maskall , J. , \& Stokes, A. (2008). Designing effective fieldwork for the environmental and natural sciences. Plymouth: Higher Education Academy Subject Centre for Geography, Earth and Environmental Sciences.

McEwen , L. (1996). Fieldwork in the undergraduate geography programme: Challenges and changes. Journal of Geography in Higher Education, 20(3), 379-384.

McLean , K. (2015). Ex-formation as a method for mapping smellscapes. Communication Design, 3(2), 173-186. doi:10.1080/20557132.2015.1163081

Muehrcke, P. (1972). Maps in geography. Cartographica: The International Journal for Geographic Information and Geovisualization, 18(2), 1-41.

NASA. (2017). Landsat 8. Retrieved December 4, 2017, from https://landsat.gsfc.nasa.gov/landsat-datacontinuity-mission/

Parks , L. (2001). Satellite views of Srebrenica: Tele-visuality and the politics of witnessing. Social Identities, 7(4), 585-611. doi:10.1080/13504630120107728

Phillips, R. (2015). Playful and multi-sensory fieldwork: Seeing, hearing and touching New York. Journal of Geography in Higher Education, 39(4), 617-629.

Phillips , R. , \& Johns , J. (2012). Fieldwork for human geography. London: Sage.

Playful Mapping Collective. (2016). Playful mapping: Playing with maps in contemporary media cultures. Amsterdam: Institute of Network Cultures. Retrieved from http://www.networkcultures.org

Ploszajska, T. (1998). Down to earth? Geography fieldwork in English schools, 1870-1944. Environment and Planning D: Society and Space, 16(6), 757-774.

Public Lab. (2013). Public lab: A DIY environmental science community. Retrieved from http://publiclab.org/

Quercia, D. , Schifanella , R. , Aiello , L. M. , \& McLean , K. (2015). Smelly maps: The digital life of urban smellscapes. Retrieved from http://arxiv.org/abs/1505.06851

Raessens , J. (2006). Playful identities, or the ludification of culture. Games and Culture, 1(1), 52-57. 
Riggs , E. M. , Lieder, C. C. , \& Balliet, R. (2009). Geologic problem solving in the field: Analysis of field navigation and mapping by advanced undergraduates. Journal of Geoscience Education, 57(1), 48-63.

Rød, J. K. , Ormeling, F. , \& van Elzakker , C. (2001). An agenda for democratising cartographic visualisation. Norsk Geografisk Tidsskrift, 55(1), 38-41.

Sander, L. (2014). Kite aerial photography (KAP) as a tool for field teaching. Journal of Geography in Higher Education, 38(3), 425-430. doi:10.1080/03098265.2014.919443

Sicart, M. (2014). Play matters. Cambridge, MA: The Massachusetts Institute of Technology Press.

Simm , D. , \& Marvell , A. (2015). Gaining a "sense of place": Students' affective experiences of place leading to transformative learning on international fieldwork. Journal of Geography in Higher Education, 39(4), 595-616.

Smith , M. J. , Paron , P. , \& Griffiths , J. S. (2011). Geomorphological mapping: Methods and applications (Vol. 15). London: Elsevier.

Sui , D. , Elwood , S. , \& Goodchild, M. (2013). Crowdsourcing geographic knowledge: Volunteered geographic information in theory and practice. Berlin: Springer Science \& Business Media.

Sutton-Smith , B. (2001). The ambiguity of play. Cambridge, MA: Harvard University Press.

Warner, W. S. (1996). Kiteography. The aerial eye, 2(2), 16-17.

Warren, J. Y. (2010). Grassroots mapping: Tools for participatory and activist cartography. Cambridge, MA: Massachusetts Institute of Technology. Retrieved from http://dspace.mit.edu/handle/1721.1/65319

Williams , R. D. , Tooth , S. , \& Gibson , M. (2017). The sky is the limit: Reconstructing physical geography from an aerial perspective. Journal of Geography in Higher Education, 41(1), 134-146.

WindGuru. (2016). Windguru - Xlendi Bay. Retrieved July 25, 2017, from https://www.windguru.cz/397647

Wundram , D. , \& Löffler , J. (2008). High-resolution spatial analysis of mountain landscapes using a low-altitude remote sensing approach. International Journal of Remote Sensing, 29(4), 961-974. doi:10.1080/01431160701352113 